\title{
Developmental and physical-fitness associations with gross motor coordination problems in Peruvian children
}

\author{
Raquel Nichele de Chaves ${ }^{\mathrm{a}, *}$, Alcibíades Bustamante Valdívia ${ }^{\mathrm{b}}$, Alan Nevill ${ }^{\mathrm{c}}$, \\ Duarte Freitas ${ }^{\mathrm{d}}$, Go Tani ${ }^{\mathrm{e}}$, Peter T. Katzmarzyk ${ }^{\mathrm{f}}$, José António Ribeiro Maia ${ }^{\mathrm{g}}$ \\ ${ }^{a}$ Department of Physical Education, Federal University of Technology - Parana, Av. Sete de Setembro, 3165, 80230901 Curitiba, PR, Brazil \\ ${ }^{\mathrm{b}}$ National University of Education Enrique Guzmán y Valle, Enrique Guzmán y Valle S/N, La Cantuta, Chosica, Lima, Peru \\ ${ }^{\mathrm{c}}$ Faculty of Education, Health and Wellbeing, University of Wolverhampton, WS1 3BD, United Kingdom \\ d Department of Physical Education and Sports, University of Madeira, Praça do Municipio, 9000-082 Funchal, Portugal \\ e School of Physical Education and Sport, University of São Paulo, Av. Professor Melo Morais, 65, Cidade Universitária, 05508-030 São Paulo, \\ Brazil \\ ${ }^{f}$ Pennington Biomedical Research Center, Louisiana State University, 6400 Perkins Rd, Baton Rouge, LA 70808, USA \\ ${ }^{\mathrm{g}} \mathrm{CIFI}^{2}$ D, Faculty of Sport, University of Porto, Rua Dr. Plácido Costa, 91, 4200-450 Porto, Portugal
}

\section{A R T I C L E I N F O}

\section{Article history:}

Received 11 April 2015

Received in revised form 5 January 2016

Accepted 6 January 2016

Available online

\section{Keywords:}

Gross motor coordination

Poor motor proficiency

Physical fitness

Children

\begin{abstract}
A B S T R A C T
The aims of this cross-sectional study were to examine the developmental characteristics (biological maturation and body size) associated with gross motor coordination problems in 5193 Peruvian children (2787 girls) aged 6-14 years from different geographical locations, and to investigate how the probability that children suffer with gross motor coordination problems varies with physical fitness. Children with gross motor coordination problems were more likely to have lower flexibility and explosive strength levels, having adjusted for age, sex, maturation and study site. Older children were more likely to suffer from gross motor coordination problems, as were those with greater body mass index. However, more mature children were less likely to have gross motor coordination problems, although children who live at sea level or at high altitude were more likely to suffer from gross motor coordination problems than children living in the jungle. Our results provide evidence that children and adolescents with lower physical fitness are more likely to have gross motor coordination difficulties. The identification of youths with gross motor coordination problems and providing them with effective intervention programs is an important priority in order to overcome such developmental problems, and help to improve their general health status.
\end{abstract}

(c) 2016 Elsevier Ltd. All rights reserved.

\section{Introduction}

There is a renewed research interest concerning the motor coordination of school-aged children (Largo, Fischer, \& Rousson, 2003; Rivilis et al., 2011) given its potential influence on a variety of outcomes. For example, children with poor motor coordination have been shown to have significant impairments in their daily tasks, from self-care and school-based

\footnotetext{
* Corresponding author.

E-mail addresses: raquelchaves@utfpr.edu.br (R.N. Chaves), huanta2609@yahoo.es (A. Bustamante Valdívia), a.m.nevill@wlv.ac.uk (A. Nevill), dfreitas@uma.pt (D. Freitas), gotani@usp.br (G. Tani), Peter.Katzmarzyk@pbrc.edu (P.T. Katzmarzyk), jmaia@fade.up.pt (J.A.R. Maia).
} 
activities to emotional and social interactions within typically developing groups (Emck, Bosscher, Beek, \& Doreleijers, 2009; Vandorpe et al., 2011). Furthermore, these children seem to be at increased risk of developing obesity and associated comorbidities due to their lower physical fitness (PF) levels, decreased participation in physical activities, and higher body fatness than their peers (Lubans, Morgan, Cliff, Barnett, \& Okely, 2010; Rivilis et al., 2011).

Gross motor coordination (GMC) is a complex trait that integrates internal neurological and neuro-motor processes (Keogh \& Sugden, 1985), and its manifold expression is generally explained in terms of additive genetic effects as well as their interaction with environmental factors (Bouchard, Malina, \& Pérusse, 1997; Chaves, Tani, Souza, Santos, \& Maia, 2012; Malina, Bouchard, \& Bar-Or, 2004). Additionally, the developmental process of GMC is dependent upon neuromuscular maturation, prior and current motor opportunities, as well as physical growth and biological maturation, which influence and mediate a variety of movement experiences (Bouchard et al., 1997; Malina et al., 2004).

With increasing age, a gradual and steady increase in motor coordination is expected, particularly among elementary school children (Antunes et al., 2015; Chaves, Tani, Souza, Baxter-Jones, \& Maia, 2013; Valdívia et al., 2008; Vandorpe et al., 2011). Yet, it is important to consider the effects of possible correlates/confounding variables associated with such increases in order to better understand their influence, confounders that previous studies might have ignored. For example, in a recent cross-sectional study, Chaves et al. (2015) showed that age effects in GMC are confounded by children's physical fitness levels as well as by their levels of body fat. Moreover, biological maturation may also play an important role in GMC development because differences in the timing and tempo in the pubertal growth spurt may induce additional difficulties in children who already have poor motor performance (Visser, Geuze, \& Kalverboer, 1998). It is also important to recognize that the available GMC research mostly used raw performance data, i.e., apparently no reports consider age differences in children with coordination problems as they grow. As children mature, they face increasing challenges in the complexity of motor tasks/tests (Fliers et al., 2008), and those children with motor coordination difficulties may develop further motor performance deficiencies with increasing age. Additionally, changes in body dimensions during puberty (Visser et al., 1998) as well as low physical fitness levels and inactivity may increase the likelihood of GMC problems (Cattuzzo et al., 2014), and it is thus possible that more mature youths may be more prone to having GMC problems.

Differences in motor proficiency between boys and girls have been reported not only in cross-sectional but also in longitudinal studies (Graf et al., 2004; Willimczik, 1980), suggesting that boys are more coordinated. These sex trends in motor proficiency are expected, and are usually explained in terms of differences in body growth and biological maturation (Malina et al., 2004). Additionally, GMC differences within and between sexes might also be explained by the differential expression of their PF characteristics (Vandorpe et al., 2011) because it has been suggested that cardiorespiratory fitness, power, muscle strength and endurance are positively associated with motor proficiency (Cattuzzo et al., 2014; Rivilis et al., 2011). Yet, the interpretation of the relationship between GMC, biological maturation and PF components is not a simple task, requiring the testing of sequential/alternative hypotheses using age, sex, physical growth and biological maturation as suitable predictors (Bouchard et al., 1997).

The effects of altitude on morphological and physiological traits affecting motor performance in Andean populations have been considered in previous studies (Greksa, 2006; Mueller, Schull, Schull, Soto, \& Rothhammer, 1978; Valdivia, Maia, \& Nevill, 2014). The results suggest that differences in geography play an important role in GMC. In Peru, three natural areas are identified: (i) the coast or coastal desert that occupies $11.7 \%$ of the total area, located between the western mountain and the Pacific Ocean, with a subtropical desert climate; (ii) the Saw or Andean region comprising 28\% of the total Peruvian area, located in the central part of the Andes mountains, with high mountain and mountain climate; (iii) and the jungle or Amazon region being the largest of the Peruvian territory, i.e., approximately $60.3 \%$, with warm and rainy tropical climate. Differences in physical activity levels marked by daily chores and subsistence activities are evident, as well as in cardiorespiratory fitness and muscular strength in children and adolescents residing at high altitude, sea level and rainforest (Valdivia et al., 2014). This may also affect GMC levels and may shed light in the interpretation of GMC differences. Thus, the purpose of the current study was to identify the developmental characteristics associated with GMC in Peruvian children, namely biological maturation and body size. A further aim was to investigate how the probability or odds that children suffer from GMC difficulties is related to PF components having controlled for the developmental characteristics (body size and biological maturation) already identified in children. This paper will address the following hypotheses: (1) boys and older children are less likely to have GMC problems than girls; (2) more mature children and those with higher BMI are more likely to have GMC problems, as well as children who live in the sea level region; (3) those more physically fit are more likely to have higher GMC.

\section{Methods}

\subsection{Participants}

The present cross-sectional sample (see Table 1) comes from the Healthy and Optimistic Growth Study conducted in Peru which investigates growth, development and health of children, adolescents and their families. A sample of 5193 adolescents (2787 girls) aged 6-14 years was obtained from 18 random public schools belonging to 4 cities located in the three natural regions of central Peru: in the coast, Barranco $(58 \mathrm{~m})$, which forms part of the province of Lima; in the Saw, Junín district $(4107 \mathrm{~m})$, in the province of the same name, and in the jungle, the districts of La Merced and San Ramon (751 $\mathrm{m}$ ) that have a geographical continuity and integrate the Chanchamayo province. Within each school all children were invited to 
Table 1

Sample size by sex, age and geographical location.

\begin{tabular}{|c|c|c|c|c|c|c|c|}
\hline \multirow[t]{2}{*}{ Age } & \multicolumn{2}{|c|}{ Barranco (sea level) } & \multicolumn{2}{|c|}{ Junin (altitude) } & \multicolumn{2}{|c|}{ Chanchamayo (jungle) } & \multirow[t]{2}{*}{ Total } \\
\hline & Boys & Girls & Boys & Girls & Boys & Girls & \\
\hline 6 & 37 & 85 & 46 & 38 & 140 & 147 & 493 \\
\hline 7 & 23 & 62 & 45 & 55 & 190 & 136 & 511 \\
\hline 8 & 30 & 71 & 60 & 47 & 174 & 176 & 558 \\
\hline 9 & 41 & 99 & 76 & 65 & 182 & 184 & 647 \\
\hline 10 & 38 & 81 & 71 & 69 & 173 & 189 & 621 \\
\hline 11 & 68 & 106 & 54 & 71 & 104 & 105 & 508 \\
\hline 12 & 113 & 91 & 87 & 130 & 112 & 152 & 685 \\
\hline 13 & 61 & 68 & 92 & 75 & 107 & 124 & 527 \\
\hline 14 & 100 & 125 & 102 & 109 & 80 & 127 & 643 \\
\hline Total & 511 & 788 & 633 & 659 & 1262 & 1340 & 5193 \\
\hline
\end{tabular}

participated and their response rate was very high ( $90 \%)$. After initial political, educational and health contacts in each city, formal permission was obtained from school authorities participating in the study. Written consent from parents and assent from children was obtained after full explanation of all procedures. The ethical committee of the National University of Education Enrique Guzmán y Valle approved the investigation.

\subsection{Anthropometry}

All measurements were made according to standardized techniques (Lohman, Roche, \& Martorell, 1988). Height and sitting height were measured to the nearest $0.1 \mathrm{~cm}$ with a portable stadiometer (Sanny, Model ES-2060), body mass was measured at the nearest $0.1 \mathrm{~kg}$ using a digital scale (Pesacon, Model IP68). BMI was obtained by the ratio of body mass to height $\left(\mathrm{kg} / \mathrm{m}^{2}\right)$ and reciprocal ponderal index (RPI) (height . mass $\left.{ }^{-0.333}\right)$ was recorded in the units $\left(\mathrm{cm}^{\mathrm{kg}} \mathrm{kg}^{-0.333}\right)$.

\subsection{Maturity offset}

Maturity offset estimates time before or after age at peak height velocity (PHV), and is a non-invasive method. Very simply, sex-specific equations were used with age, body mass, height, sitting height and leg length as predictors (Mirwald, Baxter-Jones, Bailey, \& Beunen, 2002). The maturity offset equations estimate the distance each subject is from their expected age (in years) of attainment of PHV. The value is expressed in years (either + or - ) from PHV.

\subsection{Gross motor coordination}

Gross motor coordination was evaluated with the gross motor coordination test battery, Köperkoordination Test für Kinder (KTK), developed in Germany (Kiphard \& Schilling, 1974) for children and adolescents from 6 to 14 years of age. The battery consists of four tests, namely walking backwards along a balance beam, moving sideways on boxes, hopping for height on one foot, and jumping sideways. While walking backwards, children walk three times along each of three balance beams, each with a different width. For each balance beam, a maximum of 24 steps (eight per trial, and 3 trials) were counted, with maximum of 72 steps ( 24 steps in 3 beams) for this test. For moving sideways, children move across the floor for $20 \mathrm{~s}$ (two trials) by stepping from one plate to the next, transferring to the first plate, stepping on it. The number of relocations was counted and summed over trials. When hopping for height on one foot, children jump from one leg over an increasing pile of pillows after a short run-up. The successful performance on the first trial corresponds to 3 points, on the second to 2 points and on the third trial to 1 point. A maximum of 39 points (maximum of 12 pillows) could be scored for each leg, yielding a possible maximum score of 78 points. The jumping sideways test refers to jumping laterally as many times as possible over a wooden slat in $15 \mathrm{~s}$, in two trials. The number of jumps over the two trials was summed. Following Kiphard and Schilling (1974), using scores from the four tests, the motor quotient (MQ) is calculated and expresses a global marker of GMC. This global score is adjusted for each subject's age and sex, and the MQ score classifies children into following categories: 'not possible' (MQ < 56), 'severe motor disorder' (MQ 56-70), 'moderate motor disorder' (MQ 71-85), 'normal' (MQ 86-115), 'good' (MQ 116-130) and 'high' (MQ 131-145). In the present paper two broad categories were established and used in the logistic regression analyses: schoolchildren with GMC difficulties (MQ $\leq 85$ ) and without GMC disorders $(\mathrm{MQ}>85)$.

\subsection{Physical fitness}

In this study we used four PF tests that are part of the EUROFIT battery (Committee of Experts on Sports Research) assessing static (handgrip) and explosive muscle strength (standing long-jump), flexibility (sit and reach), and speed/agility (shuttle run test). Further, abdominal muscular endurance (curl-ups) from the Fitnessgram battery (Welk \& Meredith, 2008), 
and cardiorespiratory endurance (12 min run) from American Alliance for Health, Physical Education, Recreation and Dance (AAHPERD) test battery (AAHPERD, 1988) were assessed.

\subsection{Data quality control}

Data quality control was assured in three steps. Step one corresponded to a systematic training of team members, which consisted of studying and learning all methodological procedures conducted by mentors of the project, followed by a pilot study that took place at the UNE EGyV in March 2009 with all team members. In step two, an in-field reliability procedure was used, where three to five students were randomly selected on alternating evaluation days and re-tested. Technical errors of measurement (TEM) for height and body mass, and ANOVA-based intraclass correlations (R) and corresponding 95\% confidence intervals $(95 \% \mathrm{CI})$ were used to estimate test-retest reliabilities for all GMC and PF tests: in GMC tests, $\mathrm{R}$ ranges from 0.78 (95\% CI: 0.74-0.87) for hopping on one leg over an obstacle, to $0.92(95 \% \mathrm{CI}$ : $0.88-0.96)$ in shifting platforms; for all PF tests, $\mathrm{R}$ ranged from 0.87 (95\% CI: $0.82-0.91$ ) for the $12 \mathrm{~min}$ run test, to 0.98 (95\% CI: 0.97-0.98) for the standing long jump. For anthropometric measures, height TEM $=0.2 \mathrm{~cm}$, body mass TEM $=0.1 \mathrm{~kg}$, and sitting height TEM $=0.1 \mathrm{~cm}$. Step three consisted in checking for errors in data entry, inconsistent data, and exploratory analysis done in SPSS v.20.

\subsection{Data analyses}

Binary logistic regression was used to explore which developmental characteristics (e.g., biological maturation, body size), and PF components were associated with GMC problems. This was conducted in 3 steps. By assigning the dichotomous indicator of 1 to those children identified with GMC problems as the response variable (0 to those who had no GMC problems), an initial model incorporating age and sex (boys = reference category) was analyzed (Model 1). This was subsequently adjusted for body size (BMI), maturity offset, and geographic differences (where the children lived in Peru; jungle is our reference category; area $1=$ high altitude, and area $2=$ coastal-sea level) in Model 2. Finally (Model 3 ) the other PF components (flexibility, explosive and static strength, speed/agility, and cardiorespiratory endurance) were added to the model. This final model was achieved using a backward elimination process that fits the saturated model (fitting all PF variables) and refined by removing redundant predictors until a parsimonious model is reached.

\section{Results}

Table 2 shows mean values for all variables. As expected, height, weight, and all motor performance tests increase with age; further, with the exception of sit-and-reach, boys outperform girls in all tests. Maturity offset mean values across all ages, in both boys and girls, parallels what is usually expected - girls attain PHV around 12 years, and boys around 14. Additionally, there is a systematic increase in GMC problems with increasing age. This trend is consistently more prevalent in girls.

The binary logistic regression analysis reported in Model 1 (see Table 3) identified a trend showing that with increasing age the chance of being diagnosed with GMC problems increases, and that girls are 4 times more likely than boys to have such problems ( $\mathrm{OR}=4.047,95 \% \mathrm{CI}=3.406-4.809)$. In Model 2, girls are now 6 times more likely to have been diagnosed with GMC problems, and that more mature children (assessed using maturity offset) are less likely to suffer from this problem $(\mathrm{OR}=0.526,95 \% \mathrm{CI}=0.432-0.654)$; further, those with higher $\mathrm{BMI}(\mathrm{OR}=1.526,95 \% \mathrm{CI}=1.468-1.591)$ are more likely to have GMC problems. Relative to children who live in the jungle, those who live in high altitude are about 2 times (OR $=1.960,95 \%$ $\mathrm{CI}=1.581-2.431)$ more likely to have GMC problems, while those living at sea level are about 3 times more likely $(\mathrm{OR}=2.837$, $95 \% \mathrm{CI}=2.257-3.566$ ). Finally in Model 3, when the six PF component tests were added (sit-and-reach, hand-grip strength, standing long jump, shuttle-run, curl ups and 12 min run), only two were retained (following a backward elimination process): flexibility/sit-and-reach test $(\mathrm{OR}=0.941 ; 95 \% \mathrm{CI}$ : 0.910-0.972) and explosive strength/standing long jump test ( $O R=0.979$; $95 \% \mathrm{CI}$ : $0.975-0.984)$ showing that the more flexible and stronger a child is the less likely he/she is to be diagnosed with GMC problems.

From Models 1 to 3, i.e., with increasing model complexity, there is a steady decline in the deviance (-2 Log Likelihood), an increase in the Negelkerke $R^{2}$ values, as well as in the predictive accuracy of about $87 \%$ of the cases in either group.

\section{Discussion}

This study aimed to identify developmental characteristics (biological maturation and body size) associated with GMC problems in Peruvian children, and to investigate if the probability of having GMC difficulties varied with their PF. The results suggest that children with GMC problems are more likely to have lower flexibility and explosive strength, having controlled for their age, sex, body size (BMI), biological maturation as well as study sites.

Sex differences in GMC have been previously reported favouring boys (Graf et al., 2004; Martins et al., 2010; Wrotniak, Epstein, Dorn, Jones, \& Kondilis, 2006), and our results (Model 3) suggest that girls are $\sim 5$ times more likely to have poor GMC than boys, after controlling for age, BMI, PF tests, maturity offset, and altitude. Such findings reflect a complex interaction of biological and cultural factors, which are probably linked with differential physical activities and sport participation (Malina et al., 2004). Additionally, Valdívia et al. (2008) reported that Peruvian girls usually are less involved with active games and 
Table 2

Descriptive results (means \pm standard deviations).

\begin{tabular}{|c|c|c|c|c|c|c|c|c|c|c|c|}
\hline & $\begin{array}{l}\text { Height } \\
(\mathrm{cm})\end{array}$ & $\begin{array}{l}\text { Weight } \\
(\mathrm{kg})\end{array}$ & $\begin{array}{l}\text { MatOff } \\
\text { (years) }\end{array}$ & MQ & $\mathrm{MQC}^{\mathrm{a}}$ & $\begin{array}{l}\text { HandG } \\
(\mathrm{kg})\end{array}$ & $\begin{array}{l}\text { SLJ } \\
(\mathrm{cm})\end{array}$ & $\begin{array}{l}\text { Sit-R } \\
(\mathrm{cm})\end{array}$ & $\begin{array}{l}\text { Shut-R } \\
\text { (s) }\end{array}$ & $\begin{array}{l}\text { CUP } \\
\text { (reps) }\end{array}$ & $\begin{array}{l}12^{\prime} \text { run } \\
(\mathrm{m})\end{array}$ \\
\hline \multicolumn{12}{|c|}{ Boys } \\
\hline 6 & $113.1 \pm 5.3$ & $21.1 \pm 3.3$ & $-5.7 \pm 0.2$ & $118.9 \pm 11.7$ & $1 / 222$ & $7.8 \pm 1.3$ & $94.7 \pm 18.0$ & $23.3 \pm 3.5$ & $25.6 \pm 2.4$ & $26.1 \pm 13.1$ & $1216.0 \pm 270.0$ \\
\hline 7 & $118.8 \pm 5.6$ & $23.9 \pm 4.6$ & $-5.0 \pm 0.3$ & $113.0 \pm 13.2$ & $12 / 246$ & $8.9 \pm 1.9$ & $106.1 \pm 19.2$ & $23.0 \pm 2.3$ & $24.4 \pm 2.7$ & $31.6 \pm 16.4$ & $1339.8 \pm 324.7$ \\
\hline 8 & $122.8 \pm 6.1$ & $25.9 \pm 5.0$ & $-4.4 \pm 0.4$ & $112.6 \pm 12.3$ & $10 / 254$ & $10.0 \pm 2.4$ & $113.4 \pm 17.3$ & $22.2 \pm 2.0$ & $23.7 \pm 2.6$ & $35.4 \pm 15.3$ & $1451.6 \pm 343.2$ \\
\hline 9 & $128.4 \pm 5.5$ & $29.4 \pm 5.6$ & $-3.7 \pm 0.4$ & $107.5 \pm 11.7$ & $19 / 280$ & $11.9 \pm 2.6$ & $119.6 \pm 15.1$ & $21.8 \pm 1.9$ & $23.0 \pm 2.4$ & $40.1 \pm 16.1$ & $1549.1 \pm 278.3$ \\
\hline 10 & $132.2 \pm 5.7$ & $31.7 \pm 6.9$ & $-3.0 \pm 0.4$ & $106.2 \pm 10.8$ & $16 / 266$ & $13.4 \pm 2.7$ & $123.7 \pm 18.6$ & $21.5 \pm 2.8$ & $22.2 \pm 2.4$ & $43.8 \pm 15.9$ & $1660.1 \pm 275.3$ \\
\hline 11 & $138.4 \pm 7.4$ & $37.5 \pm 9.1$ & $-2.1 \pm 0.6$ & $99.5 \pm 13.3$ & $35 / 191$ & $15.3 \pm 3.1$ & $127.7 \pm 16.8$ & $21.2 \pm 1.7$ & $22.0 \pm 1.7$ & $47.1 \pm 12.9$ & $1684.3 \pm 273.2$ \\
\hline 12 & $145.6 \pm 8.7$ & $42.3 \pm 11.0$ & $-1.2 \pm 0.7$ & $101.1 \pm 13.7$ & $39 / 273$ & $19.0 \pm 4.2$ & $133.2 \pm 18.1$ & $20.8 \pm 2.8$ & $21.6 \pm 1.4$ & $50.8 \pm 13.5$ & $1740.3 \pm 289.6$ \\
\hline 13 & $150.6 \pm 8.9$ & $44.7 \pm 10.1$ & $-0.3 \pm 0.7$ & $99.5 \pm 14.1$ & $34 / 226$ & $21.6 \pm 5.2$ & $137.3 \pm 22.3$ & $21.0 \pm 2.7$ & $21.5 \pm 1.8$ & $54.1 \pm 14.3$ & $1816.0 \pm 317.7$ \\
\hline 14 & $157.2 \pm 8.4$ & $50.3 \pm 10.7$ & $0.7 \pm 0.7$ & $97.0 \pm 14.5$ & $50 / 232$ & $25.7 \pm 6.4$ & $145.5 \pm 23.8$ & $21.1 \pm 3.4$ & $21.6 \pm 2.1$ & $55.7 \pm 14.9$ & $1847.3 \pm 397.6$ \\
\hline \multicolumn{12}{|c|}{ Girls } \\
\hline 6 & $113.0 \pm 5.4$ & $21.4 \pm 3.9$ & $-5.0 \pm 0.3$ & $100.0 \pm 13.8$ & $4 / 266$ & $7.5 \pm 1.1$ & $87.8 \pm 17.0$ & $23.8 \pm 3.7$ & $26.9 \pm 3.3$ & $23.0 \pm 13.7$ & $1129.2 \pm 254.0$ \\
\hline 7 & $118.4 \pm 5.5$ & $23.9 \pm 4.4$ & $-4.4 \pm 0.3$ & $101.4 \pm 12.3$ & $26 / 227$ & $8.2 \pm 1.4$ & $96.8 \pm 18.9$ & $23.1 \pm 3.8$ & $26.0 \pm 2.4$ & $27.1 \pm 14.0$ & $1234.2 \pm 250.9$ \\
\hline 8 & $124.2 \pm 6.0$ & $26.7 \pm 5.4$ & $-3.7 \pm 0.4$ & $103.3 \pm 13.9$ & $36 / 258$ & $9.5 \pm 2.2$ & $107.0 \pm 16.5$ & $22.9 \pm 3.9$ & $24.8 \pm 2.4$ & $31.5 \pm 15.9$ & $1291.8 \pm 265.9$ \\
\hline 9 & $129.5 \pm 6.7$ & $29.9 \pm 6.9$ & $-3.0 \pm 0.5$ & $101.0 \pm 12.5$ & $45 / 303$ & $10.9 \pm 2.4$ & $111.9 \pm 16.1$ & $22.4 \pm 3.5$ & $24.3 \pm 2.7$ & $34.9 \pm 15.0$ & $1375.3 \pm 232.1$ \\
\hline 10 & $135.2 \pm 7.5$ & $33.1 \pm 7.5$ & $-2.3 \pm 0.5$ & $94.0 \pm 12.0$ & $76 / 263$ & $12.8 \pm 3.2$ & $118.2 \pm 21.1$ & $22.1 \pm 1.3$ & $23.7 \pm 2.0$ & $37.7 \pm 17.0$ & $1449.7 \pm 255.2$ \\
\hline 11 & $141.9 \pm 7.7$ & $39.2 \pm 9.9$ & $-1.4 \pm 0.6$ & $88.0 \pm 11.9$ & $121 / 161$ & $15.3 \pm 3.4$ & $118.7 \pm 19.2$ & $21.6 \pm 2.1$ & $23.8 \pm 2.2$ & $38.9 \pm 14.1$ & $1516.3 \pm 350.7$ \\
\hline 12 & $145.6 \pm 6.1$ & $41.9 \pm 8.9$ & $-0.6 \pm 0.5$ & $93.2 \pm 11.4$ & $83 / 290$ & $17.1 \pm 3.7$ & $124.3 \pm 17.6$ & $21.8 \pm 2.0$ & $23.5 \pm 1.8$ & $41.1 \pm 15.2$ & $1567.8 \pm 251.0$ \\
\hline 13 & $149.5 \pm 5.5$ & $46.0 \pm 8.5$ & $0.1 \pm 0.4$ & $87.4 \pm 13.7$ & $121 / 146$ & $19.2 \pm 4.2$ & $124.8 \pm 18.3$ & $21.9 \pm 3.1$ & $23.8 \pm 2.1$ & $41.2 \pm 16.4$ & $1594.7 \pm 273.7$ \\
\hline 14 & $150.9 \pm 5.5$ & $48.5 \pm 8.9$ & $0.8 \pm 0.4$ & $82.5 \pm 13.2$ & $217 / 144$ & $20.7 \pm 5.1$ & $127.2 \pm 20.6$ & $21.8 \pm 3.3$ & $24.1 \pm 2.4$ & $41.9 \pm 14.6$ & $1599.5 \pm 304.2$ \\
\hline
\end{tabular}

MatOff = maturity offset, $M Q=$ motor quotient, HandG = hand grip, SLJ = standing long jump, Sit-R = sit and reach, Shut-R = shuttle run, CUP = curl up, $12^{\prime}$ run $=12$ min run.

a MQC: at each age group values correspond to schoolchildren with gross motor coordination difficulties (MQ $\leq 85)$ and without gross motor coordination disorders (MQ > 85). For example: 10 years old girls (76/263); 76 are schoolchildren with coordination difficulties 263 without gross motor coordination problems.

Table 3

Logistic regression main results for Models 1-3.

\begin{tabular}{|c|c|c|c|c|c|c|}
\hline \multirow[t]{2}{*}{ Variables } & \multicolumn{2}{|l|}{ Model 1} & \multicolumn{2}{|l|}{ Model 2} & \multicolumn{2}{|l|}{ Model 3} \\
\hline & OR & $95 \% \mathrm{CI}$ for OR & OR & $95 \% \mathrm{CI}$ for OR & OR & $95 \% \mathrm{CI}$ for OR \\
\hline Age (6 yrs) & 0.012 & $0.005-0.031$ & 0.001 & $0.000-0.006$ & 0.001 & $0.000-0.005$ \\
\hline Age (7 yrs) & 0.017 & $0.073-0.155$ & 0.016 & $0.005-0.051$ & 0.014 & $0.004-0.045$ \\
\hline Age (8 yrs) & 0.115 & $0.083-0.163$ & 0.023 & $0.008-0.063$ & 0.022 & $0.008-0.062$ \\
\hline Age (9 yrs) & 0.140 & $0.102-0.191$ & 0.032 & $0.014-0.077$ & 0.031 & $0.013-0.074$ \\
\hline Age (10 yrs) & 0.223 & $0.168-0.296$ & 0.083 & $0.040-0.169$ & 0.084 & $0.041-0.175$ \\
\hline Age (11 yrs) & 0.599 & $0.463-0.773$ & 0.231 & $0.131-0.407$ & 0.227 & $0.128-0.404$ \\
\hline Age (12 yrs) & 0.282 & $0.217-0.366$ & 0.124 & $0.080-0.191$ & 0.123 & $0.079-0.192$ \\
\hline Age (13 yrs) & 0.600 & $0.464-0.776$ & 0.452 & $0.332-0.633$ & 0.445 & $0.317-0.626$ \\
\hline Age (14 yrs) & 1.00 & & 1.00 & & 1.00 & \\
\hline Sex (male) & 1.00 & & 1.00 & & 1.00 & \\
\hline Sex (female) & 4.047 & $3.047-4.809$ & 6.624 & $5.281-8.309$ & 5.445 & $4.296-6.900$ \\
\hline Maturity offset & & & 0.526 & $0.432-0.654$ & 0.591 & $0.473-0.738$ \\
\hline BMI & & & 1.528 & $1.468-1.591$ & 1.505 & $1.602-2.507$ \\
\hline Area (jungle) & & & 1.00 & & 1.00 & \\
\hline Area 1 (high altitude) & & & 1.960 & $1.581-2.431$ & 2.004 & $1.602-2.507$ \\
\hline Area 2 (coastal/sea level) & & & 2.837 & $2.257-3.566$ & 2.397 & $1.890-4.040$ \\
\hline Flexibility & & & & & 0.941 & $0.910-0.972$ \\
\hline Standing long jump & & & & & 0.979 & $0.975-0.984$ \\
\hline Constant & -1.176 & & -10.423 & & -5.948 & \\
\hline-2 Log Likelihood & \multicolumn{2}{|c|}{4073.218} & \multicolumn{2}{|c|}{3310.448} & \multicolumn{2}{|c|}{3224.232} \\
\hline Negelkerke $R^{2}$ & \multicolumn{2}{|c|}{0.247} & \multicolumn{2}{|c|}{0.437} & \multicolumn{2}{|c|}{0.456} \\
\hline Precision of classification & \multicolumn{2}{|c|}{$83.2 \%$} & \multicolumn{2}{|c|}{$86.3 \%$} & \multicolumn{2}{|c|}{$86.9 \%$} \\
\hline
\end{tabular}

The baseline reference group was 14 year old boys living in the jungle.

dedicate less time to these practices compared to boys, and that parents are more lenient with male children who translates into providing greater opportunities for the practice of sports and recreational activities.

Our Peruvian data suggest (Model 3) that as children grow older they appear to be more likely to have GMC problems; further, it also shows that more mature children are less likely to show GMC problems. We had hypothesized that older children would have fewer GMC problems than younger children, given the existing evidence that GMC generally increases with age. However, given that the definition of GMC "problems" is adjusted for age (see methods), it does not follow that 
generalized increases in GMC with age correspond with the prevalence of age-specific problems or deficiencies. It is possible that during the pubertal growth spurt children may become clumsier due to non-synchronicity in the growth of different body parts as well as in their proportions which may express biomechanical changes produced by the growth velocity associated with adaptive alterations in sensorimotor system (Visser et al., 1998). On the other hand, the interpretation of biological maturation affecting GMC is not an easy task as little data are available, and evidence is mostly related to PF traits (Malina et al., 2004). Biological maturation is sometimes considered a confounding factor in motor performance, given that increments in speed, endurance and power have been observed around the time of age at peak height velocity (Philippaerts et al., 2006). Vandendriessche et al. (2012) studied how biological maturation may affect fitness and motor coordination skills, but in a specific sample - male soccer players aged 15-16 years. These authors reported that more mature players outperformed their later maturing peers on almost all fitness tests, but motor coordination tests assessed by KTK battery did not differentiate the more mature group from their latter peers. The contrast between these results and our findings are difficult to interpret given the many differences in the study design, age range, sample size and its specificity (only males soccer players).

The present study suggests that GMC levels may be negatively associated with BMI, controlling for age, sex and altitude sites. Some reports to date have shown negative associations between BMI and GMC (Antunes et al., 2015; D'Hondt et al., 2011; Graf et al., 2004; Lopes, Stodden, Bianchi, Maia, \& Rodrigues, 2012; Martins et al., 2010). A recent longitudinal study showed that GMC developmental levels were strongly related to children's weight status, attributed to BMI, per se, a negative role in predicting motor competence (D'Hondt et al., 2014). Tsiotra, Nevill, Lane, and Koutedakis (2009) showed that children with GMC disorders tend to be less engaged in general physical activities and suggested that this may be partly attributable to their higher BMI since it directly affects performance in body-mass-dependent activities.

The three Peruvian geographic areas, namely sea-level, rainforest and high altitude were identified as relevant factors to the likelihood of showing GMC problems. Very briefly, sea-level refers to the coast or coastal desert with a subtropical desert climate; high altitude area is the Andean region, central part of the Andes mountain and shows a high mountain and mountain climate; and the rainforest area, i.e., the jungle or Amazon region has warm tropical climate and is a rainy area (Instituto Nacional de Estadística e Informática, 2005). Valdivia et al. (2014) found motor performance differences among children and adolescents from these three natural regions, where rainforest children outperform the others in muscular strength and agility tests. According to the authors (Valdivia et al., 2014) and data from the National Health Institute of Peru (Instituto Nacional de Salud, 2005), amazon locations seem to favour schoolchildren to diversify and maximize their motor skills associated with physical activity levels and patterns, structured or unstructured, linked to the tropical climate and environmental conditions. In sea-level areas, conditions are less favourable to adopting healthy active lifestyles, and consequently there are less motor opportunities for children due to high population, serious problems of traffic congestion and public insecurity. High altitude residents suffer with severe climate which creates a lot of difficulties in their sport and physical activity participation (Instituto Nacional de Estadística e Informática, 2005, 2008; Instituto Nacional de Salud, 2005).

The present study suggests that children with less explosive strength and limited flexibility are more likely to have GMC problems. Although we were not able to identify any study that has independently explored the differences and associations between PF components and GMC controlling for several other relevant covariates, in general there is a body of evidence suggesting that PF components are linked to motor skill refinement, mainly cardiorespiratory and musculoskeletal fitness (Cairney, Hay, Wade, Faught, \& Flouris, 2006; Cantell, Crawford, \& Tish Doyle-Baker, 2008; Cattuzzo et al., 2014; Hands \& Larkin, 2006). The association between flexibility and GMC has not been widely explored. Available results are lacking, and mostly suggest a low association between GMC and flexibility (Cattuzzo et al., 2014). A possible reason for differences between Peruvian data and those from previous studies may be linked to the fact that GMC tests also comprise dynamic balance tasks, which may be related to explosive muscle strength.

In a reverse pathway, children with motor difficulties usually find simple motor tasks challenging, thus decreasing their PF development and associated GMC (Rivilis et al., 2011; Stodden et al., 2008). In general, individuals with low motor competence exhibit inferior overall PF levels than peers with higher motor competence (Cantell et al., 2008). The reasons for this have not been extensively investigated, although some results indicated that psychological factors may play important roles, namely perceived motor competence, which may reduce physically active pursuits (Cairney et al., 2006). Physical activities and sports engagement often require significant levels of PF, i.e., flexibility, muscular strength, agility and cardiorespiratory endurance. Children and adolescents who show minimal motor and physical competence to practice may believe themselves inadequate in regards to their peers with high motor competence, leading them to giving up participation (Cairney et al., 2006; Cantell et al., 2008). Thus, a serious negative participation cycle and hypoactivity tend to be established with implications for GMC problems in childhood and adolescence (Cantell et al., 2008; Stodden et al., 2008).

It is important to highlight that the abovementioned GMC predictors are not the sole factors affecting performance in motor coordination tasks, but also the variety of other physical activities as well as participation in sports during childhood and adolescence (Stodden et al., 2008; Visser et al., 1998). Adequate amounts of physical activity and/or sport participation may improve motor coordination levels both in pre-pubertal and pubertal children (Stodden et al., 2008). Differences in activities of daily living and/or daily chores of schoolchildren residing in different geographic, socio-economic and cultural contexts may also help explaining differences in the number of schoolchildren with motor coordination problems (Tsiotra et al., 2006). Moreover, it is possible that the socio-economic status of the families of the different regions may also play a moderator/mediator role in GMC levels, though families are rather similar in their SES given that all children/adolescents are 
in public schools. It has also been suggested that the family context may enable the development of fundamental motor skills and motor coordination, but the available information is only for children below 3 years of age (Barnett, Hinkley, Okely, \& Salmon, 2013; Cools, De Martelaer, Samaey, \& Andries, 2011).

This study has limitations, and need to be considered. The cross-sectional study design limits the interpretation of causal associations. The maturity offset is an indirect measure of somatic maturation, which does not have a systematic crossculturally validation across "developing countries"; however, this method has been used in previous research, mainly due to difficulties in assessing skeletal or sexual maturity in large samples. Further, all maturity estimates using the "classic" indicators have known problems when used in other populations. Secondly, the inclusion of objective PA measures (accelerometers and/or pedometers) would contribute, in a more precise way, to understanding its differential links with GMC and PF. Yet, given the large study sample size (thousands), the geographical locations and financial cost to run the study, this option was unfeasible. Although the KTK test battery has been extensively used in research conducted in recent years in several countries, it is not without limitations, most probably linked to missing tasks related to ball skill tasks as well as locomotion. Yet, its construct validity has made it valuable to use in clinical and educational settings (Kiphard \& Schilling, 1974), as well as in studies that analyzed the relationship between PF and GMC (Cattuzzo et al., 2014). Even though we did not explicitly address the relative roles of school-level variables in explaining GMC of Peruvian children/adolescents, we have to acknowledge that our design contains a hierarchical data structure - students nested within schools. Not considering this fact implies a certain bias in calculating standard-errors and thereby $p$-values associated with all parameter estimates in the Logistic regression. Yet, the variance accounted for by the school-level context is estimated to be $12 \%$, and in turn $88 \%$ of the total variance in GMC is explained by student-level variables. Further, given our sample size (thousands of subjects) we are confident enough that the bias in standard-errors is negligible, our results trustworthy, and our conclusions sound.

Notwithstanding these limitations, this study has also several strengths. Firstly, the large sample size of children across a large age range, which are important issues when discussing the precision of logistic regression results. Secondly, it is the first time that a study of GMC controls for differences in body size and other confounding variables, namely age, sex and altitude sites. In our opinion this is a novel approach to the emergent research on contributing factors of children and adolescents' GMC.

\section{Conclusions}

In conclusion, we have identified that the probability of GMC problems is considerably lower in children who have greater flexibility and explosive strength. Interestingly, more mature children are less likely to have GMC problems, after controlling for age, sex, geographical location and BMI. Furthermore, girls and children who live at sea level or attitude were more likely to have GMC problems. Taken together these results highlight those who are more likely to have GMC difficulties, suggesting individuals who might be targeted in strategies to improve GMC levels. These strategies include motor competence improvements using structured opportunities linked to sports participation and other physical activities. In turn, this may translate into increases in children's general health status, as well as reduce the prevalence of motor development problems.

\section{Competing interests}

None.

\section{Acknowledgements}

The authors thank (1) the Portuguese Foundation for Science and Technology for the support grant (SFRH/BD/43305/ 2008), (2) all the schoolchildren of Barranco, Junín and Chanchamayo who participated in this study, (3) all students and teachers of the UNE's Physical Education who participated in the data collection. Finally, a recognition to Prof. Dr. Gaston Beunen $\dagger$ who was one of the main promoters of the Healthy and Optimistic Growth Study in Peru.

\section{References}

AAHPERD (1988). Physical best. A physical fitness education and assessment program best. Reston, VA: The Alliance.

Antunes, A. M., Maia, J. A., Stasinopoulos, M. D., Gouveia, É. R., Thomis, M. A., Lefevre, J. A., et al. (2015). Gross motor coordination and weight status of Portuguese children aged 6-14 years. American Journal of Human Biology, 27, 681-689.

Barnett, L., Hinkley, T., Okely, A. D., \& Salmon, J. (2013). Child, family and environmental correlates of children's motor skill proficiency. Journal of Science and Medicine in Sport, 16, 332-336.

Bouchard, C., Malina, R. M., \& Pérusse, L. (1997). Genetics of fitness and physical performance. Champaign, IL: Human Kinetics.

Cairney, J., Hay, J. A., Wade, T. J., Faught, B. E., \& Flouris, A. (2006). Developmental coordination disorder and aerobic fitness: Is it all in their heads or is measurement still the problem? American Journal of Human Biology, 18, 66-70.

Cantell, M., Crawford, S. G., \& Tish Doyle-Baker, P. K. (2008). Physical fitness and health indices in children, adolescents and adults with high or low motor competence. Human Movement Science, 27, 344-362.

Cattuzzo, M. T., Dos Santos Henrique, R., Re, A. H., de Oliveira, I. S., Melo, B. M., de Sousa Moura, M., et al. (2014). Motor competence and health related physical fitness in youth: A systematic review. Journal of Science and Medicine in Sport.

Chaves, R., Baxter-Jones, A., Gomes, T., Souza, M., Pereira, S., \& Maia, J. (2015). Effects of individual and school-level characteristics on a child's gross motor coordination development. International Journal of Environmental Research and Public Health, 12, 8883-8896. 
Chaves, R. N. d., Tani, G., Souza, M. C. d., Baxter-Jones, A., \& Maia, J. (2013). Desempenho coordenativo de crianças: construção de cartas percentílicas baseadas no método LMS de Cole e Green. Revista Brasileira de Educação Física e Esporte, 27, 25-42.

Chaves, R. N. d., Tani, G., Souza, M. C. d., Santos, D., \& Maia, J. (2012). Variabilidade na coordenação motora: uma abordagem centrada no delineamento gemelar. Revista Brasileira de Educação Física e Esporte, 26, 301-311.

Cools, W., De Martelaer, K., Samaey, C., \& Andries, C. (2011). Fundamental movement skill performance of preschool children in relation to family context. Journal of Sports Sciences, 29, 649-660.

D’Hondt, E., Deforche, B., Gentier, I., Verstuyf, J., Vaeyens, R., De Bourdeaudhuij, I., et al. (2014). A longitudinal study of gross motor coordination and weight status in children. Obesity, 22, 1505-1511.

D'Hondt, E., Deforche, B., Vaeyens, R., Vandorpe, B., Vandendriessche, J., Pion, J., et al. (2011). Gross motor coordination in relation to weight status and age in 5- to 12-year-old boys and girls: A cross-sectional study. International Journal of Pediatric Obesity, 6, e556-e564.

Emck, C., Bosscher, R., Beek, P., \& Doreleijers, T. (2009). Gross motor performance and self-perceived motor competence in children with emotional, behavioural, and pervasive developmental disorders: A review. Developmental Medicine and Child Neurology, 51, $501-517$.

Fliers, E., Rommelse, N., Vermeulen, S. H., Altink, M., Buschgens, C. J., Faraone, S. V., et al. (2008). Motor coordination problems in children and adolescents with ADHD rated by parents and teachers: Effects of age and gender. Journal of Neural Transmission, 115, 211-220.

Graf, C., Koch, B., Kretschmann-Kandel, E., Falkowski, G., Christ, H., Coburger, S., et al. (2004). Correlation between BMI, leisure habits and motor abilities in childhood (CHILT-project). International Journal of Obesity and Related Metabolic Disorders, 28, 22-26.

Greksa, L. P. (2006). Growth and development of Andean high altitude residents. High Altitude Medicine E' Biology, 7, $116-124$.

Hands, B., \& Larkin, D. (2006). Physical fitness differences in children with and without motor learning difficulties. European Journal of Special Needs Education, 21, 447-456.

Instituto Nacional de Estadística e Informática (2005). Anuario de Estadísticas Ambientales. Lima: INEI.

Instituto Nacional de Estadística e Informática (2008). Perfil Sociodemográfico del Perú. Lima: INEI.

Instituto Nacional de Salud (2005). Encuesta Nacional de Indicadores Nuricionales, Bioquímicos, Socioeconómicos y Culturales Relacionados con las Enfermedades Crónicas Degenerativas. Lima: INS.

Keogh, J., \& Sugden, D. (1985). Movement skill development. New York: Macmillan.

Kiphard, E. J., \& Schilling, F. (1974). Köperkoordinationtest für Kinder. Weinheim: Beltz Test GmbH.

Largo, R. H., Fischer, J. E., \& Rousson, V. (2003). Neuromotor development from kindergarten age to adolescence: Developmental course and variability. Swiss Medical Weekly, 133, 193-199.

Lohman, T., Roche, A., \& Martorell, R. (1988). Anthropometric Standardization Reference Manual. Champaign, IL: Human Kinetics Books.

Lopes, V. P., Stodden, D. F., Bianchi, M. M., Maia, J. A., \& Rodrigues, L. P. (2012). Correlation between BMI and motor coordination in children. Journal of Science and Medicine in Sport, 15, 38-43.

Lubans, D. R., Morgan, P. J., Cliff, D. P., Barnett, L. M., \& Okely, A. D. (2010). Fundamental movement skills in children and adolescents: Review of associated health benefits. Sports Medicine, 40, 1019-1035.

Malina, R. M., Bouchard, C., \& Bar-Or, O. (2004). Growth, maturation and physical activity. Champaign, IL: Human Kinetics.

Martins, D., Maia, J., Seabra, A., Garganta, R., Lopes, V., Katzmarzyk, P., et al. (2010). Correlates of changes in BMI of children from the Azores islands. International Journal of Obesity, 34, 1487-1493.

Mirwald, R. L., Baxter-Jones, A. D., Bailey, D. A., \& Beunen, G. P. (2002). An assessment of maturity from anthropometric measurements. Medicine and Science in Sports and Exercise, 34, 689-694.

Mueller, W. H., Schull, V. N., Schull, W. J., Soto, P., \& Rothhammer, F. (1978). A multinational Andean genetic and health program: Growth and development in an hypoxic environment. Annals of Human Biology, 5, 329-352.

Philippaerts, R. M., Vaeyens, R., Janssens, M., Van Renterghem, B., Matthys, D., Craen, R., et al. (2006). The relationship between peak height velocity and physical performance in youth soccer players. Journal of Sports Sciences, 24, 221-230.

Rivilis, I., Hay, J., Cairney, J., Klentrou, P., Liu, J., \& Faught, B. E. (2011). Physical activity and fitness in children with developmental coordination disorder: A systematic review. Research in Developmental Disabilities, 32, 894-910.

Stodden, D., Goodway, J., Langendorfer, S., Roberton, M. A., Rudisill, M., Garcia, C., et al. (2008). A developmental perspective on the role of motor skill competence in physical activity: An emergent relationship. Quest, 60, 290-306.

Tsiotra, G. D., Flouris, A. D., Koutedakis, Y., Faught, B. E., Nevill, A. M., Lane, A. M., et al. (2006). A comparison of developmental coordination disorder prevalence rates in Canadian and Greek children. Journal of Adolescent Health: Official Publication of the Society for Adolescent Medicine, $39,125-127$.

Tsiotra, G. D., Nevill, A. M., Lane, A. M., \& Koutedakis, Y. (2009). Physical fitness and developmental coordination disorder in Greek children. Pediatric Exercise Science, 21, 186-195

Valdívia, A. B., Cartagena, L. C., Sarria, N. E., Távara, I. S., Seabra, A., Silva, R. G., et al. (2008). Coordinación Motora: Influencia de la edad, sexo, estatus socioeconómico y niveles de adiposidad en niños peruanos. Revista Brasileira de Cineantropometria e Desempenho Humano, 10, 25-34.

Valdivia, A. B., Maia, J., \& Nevill, A. (2014). Identifying the ideal body size and shape characteristics associated with children's physical performance tests in Peru. Scandinavian Journal of Medicine and Science in Sports, 25, e155-e165.

Vandendriessche, J. B., Vaeyens, R., Vandorpe, B., Lenoir, M., Lefevre, J., \& Philippaerts, R. M. (2012). Biological maturation, morphology, fitness, and motor coordination as part of a selection strategy in the search for international youth soccer players (age 15-16 years). Journal of Sports Sciences, 30, 1695-1703.

Vandorpe, B., Vandendriessche, J., Lefevre, J., Pion, J., Vaeyens, R., Matthys, S., et al. (2011). The KorperkoordinationsTest fur Kinder: Reference values and suitability for 6-12-year-old children in Flanders. Scandinavian Journal of Medicine and Science in Sports, 21, $378-388$.

Visser, J., Geuze, R. H., \& Kalverboer, A. F. (1998). The relationship between physical growth, the level of activity and the development of motor skills in adolescence: Differences between children with DCD and controls. Human Movement Science, 17, 573-608.

Welk, G. J., \& Meredith, M. D. (2008). Fitnessgram/Activitygram Reference Guide. Dallas, TX: The Cooper Institute.

Willimczik, K. (1980). Development of motor control capability (body coordination) of 6-to 10-year-old children: Results of a Longitudinal Study. In M. Ostyn, G. Beunen, \& J. Simons (Eds.), Kinanthropometry II (pp. 328-346). Baltimore: University Park Press.

Wrotniak, B. H., Epstein, L. H., Dorn, J. M., Jones, K. E., \& Kondilis, V. A. (2006). The relationship between motor proficiency and physical activity in children. Pediatrics, 118, e1758-e1765. 